\title{
Parentalidades wapichana: formas de nominação pessoal
}

\author{
Fabio de Sousa Lima ${ }^{1}$ \\ Instituto Federal de Roraima \\ Danielle dos Santos Pereira Lima² \\ Olendina de Carvalho Cavalcante 3 \\ Universidade Federal de Roraima
}

Resumo: Este artigo discute alguns traços da complexa rede de relações parentais Wapichana. Nesse sentido, engloba a influência que as preocupações parentais exercem sobre as relações conjugais nativas, tomando como polo das discussões a atribuição de nomes culturais indígenas que reforçam a influência da residência matrilocal nas relações conjugais. Trata-se de uma pesquisa etnográfica cujos resultados demonstram que a satisfação conjugal relaciona-se diretamente com as preocupações parentais.

Palavras-chave: Wapichana; Parentalidade; Residência matrilocal. 


\title{
Wapishana parentality: forms of personal nomination
}

\begin{abstract}
This article discusses some features of Wapishana's complex network of parental relationships. In this sense, it encompasses the influence that parental concerns exert on native marital relations, taking as the pole of the discussions the attribution of indigenous cultural names that reinforce the influence of matrilocal residence in conjugal relationships. It is an ethnographic research whose results show that marital satisfaction is directly related to parental concerns.
\end{abstract}

Keywords: Wapichana; Parenting; Matrilocal residence.

\section{La parentalidad entre los Wapichana: formas de nominación personal}

Resumen: Este artículo discute algunos rasgos de la compleja red de relaciones parentales Wapichana. En ese sentido, engloba la influencia que las preocupaciones parentales ejercen sobre las relaciones conyugales nativas, tomando como polo de las discusiones la atribución de nombres culturales indígenas que refuerzan la influencia de la residencia matrilocal en las relaciones conyugales. Se trata de una investigación etnográfica cuyos resultados demuestran que la satisfacción conyugal se relaciona directamente con las preocupaciones parentales.

Palabras clave: Wapichana; la paternidad; Residencia matrilocal. 
$\mathrm{E}$ ste artigo nasce da reflexão sobre as estratégias de autorreconhecimento de povos indígenas das Terras Baixas da América do Sul ${ }^{4}$ (VIVEIROS DE CASTRO, 1996; HUGH-JONES, 2002), doravante terras baixas. A pesquisa contempla em particular o ato de atribuir nomes designativos e autodesignativos pessoais entre os Wapichana e como tal prática repercute na noção nativa de parentalidade. Segundo Calavia Sáez (2016, p. 154), tem predominado nos últimos decênios a autodesignação na Amazônia ocidental. O pressuposto que o autor arrola é o de que os índios tratam tais designações como "nomes verdadeiros, que são, como se entende, aqueles que um povo usaria para falar de si mesmo". A implicação que deriva de um nome designativo ou autodesignativo não resulta apenas do fato de que esse "nome verdadeiro" emerge de uma indagação direta sobre como alguém se chama, mas também porque a resposta dada a tal pergunta tende a incluir uma locução adjetiva ou um adjetivo deste tipo: "homens de verdade" ou "humanos legítimos".

$\mathrm{Na}$ literatura antropológica, o termo parentalidade abrange a noção de maternidade e de paternidade. Trata-se de um neologismo cujo propósito é suprir a falta de uma palavra em português que traduza, com precisão, o termo parenthood (GOODY, 1982) existente na língua inglesa. A antropóloga inglesa Esther Goody, ao estudar o povo Gonja do norte de Gana, situa a parentalidade em cinco elementos distintos, a saber, a forma de conceber e colocar-se no mundo (ou seja, a cosmovisão nativa), a oferta de uma identidade provinda do local de nascimento, as formas de alimentação e a garantia da passagem da criança ao estatuto de adulto. Todos os aspectos citados sugerem formas de filiação parental. No presente estudo nos deteremos apenas no primeiro elemento haja vista que a pretensão é demonstrar a forma como os Wapichana concebem a si e se colocam no mundo pela via da designação ou autodesignação nominal pessoal, em outras palavras como se veem como pessoa, "pidian".

Ao analisar a noção de parentalidade wapichana, Farage (1997) sumariza o número de consanguíneos em quatro parentes primários, a saber, o pai ("padary”), a mãe (“daru”), os irmãos e os filhos do Ego5. É justamente esse recorte parental que é utilizado neste artigo. O ponto de partida para a compreensão dos aspectos do parentesco, insiste Sahlins (2013), é a experiência, entendida dentro de quadros mais amplos e entre distintas culturas e diferentes épocas históricas. Segundo o referido autor, as práticas cotidianas de parentesco abrangem o percurso de uma vida e reiteram os processos de sociabilidades.

\footnotetext{
${ }^{4} \mathrm{O}$ conceito de terras baixas não é consensual na etnografia, há quem o considere um recurso conceitual generalizador, como Cavalcanti-Schiel (2014: 251), tendo em vista que supostamente consagra uma divisão entre as terras altas e as terras baixas da América do Sul como domínios etnográficos diferentes.

$5 \mathrm{Na}$ teoria do parentesco, refere-se àquela pessoa que, por princípio de linearidade, serve de base para se estudar a dinâmica das gerações ascendentes e as descendentes.
} 
Entre os Wapichana, além dos consanguíneos, a filiação parental também ocorre por afinidade efetiva, a exemplo dos cunhados e genros; por afinidade virtual cognática que presume primos cruzados e tios maternos; e, também, por afinidade potencial designada pelos cognatos distantes (parentes consanguíneos) ou os não cognatos (parentes por afinidade), os quais são acoplados à família por uma espécie de "consanguinidade fictícia" - o termo aqui é tomado de empréstimo de Descola (1993, p. 174), guardando as devidas reservas. A fala de Pimidy, o beija-flor wapichana, é bem sugestiva nesse sentido:

\begin{abstract}
Pimidy: A gente, os Wapichana, tem o costume de chamar o pai da noiva de tio. Não é só eu, meus irmão tudinho chama assim.

Entrevistador: Mas, no seu caso, o pai da sua esposa é seu tio de sangue. Você me falou que ele é seu tio.

Pimidy: Sim. Mas ele é meu tio de sangue e meu tio de consideração. Se num fosse meu tio de sangue ia chamar de tio do mesmo jeito. A minha sogra não é minha tia e eu chamo ela de tia (o8/10/2017).
\end{abstract}

A parentalidade traz para o primeiro plano formas onomásticas ${ }^{6}$ pelas quais uma genealogia da pessoa pode ser modelada (SILVA, 2017), ou seja, prevalece a ideia de que também há vínculos parentais pela consideração, respeito e afeto que se nutre por alguém. Na Língua Wapichana, há dois termos nativos que sugerem a ideia de parentalidade, ou seja, "paunary", quando se faz menção de parente por afinidade, como é o caso da nora, "dinizu", não consanguínea, e "iriben”, quando se refere aos consanguíneos, como algum tio, "taatain”.

A forma onomástica que se alude no parágrafo anterior concerne aos nominativos pessoais de designação dados não pela ocasião de um nascimento de uma criança, mas por quem ela é ou o lugar que ocupa na noção de família wapichana. Desse modo, a nominação pessoal nativa modula, entre os Wapichana, a maneira como a pessoa é citada em narrativas ou como é descrita em genealogias. O que foi dito aqui, no campo da abstração, aparece na prática na fala de um Wapichana morador da aldeia Malacacheta, região da Serra da Lua: "Meu nome é Xaburu", filho de Mukau ${ }^{8}$, filho de Pizut", o último é meu dukuz [avô], há também a minha tia, wa'anyy, que na verdade é minha sogra" (27/09/2017). A pertinência da noção de parentalidade para o contexto etnográfico em questão diz respeito à percepção do que é a família wapichana, haja vista que, em uma consaguinidade fictícia, construída sobre laços de afinidade, o reconhecimento de um "paunary" depende do afeto que por ele é nutrido. O vínculo familiar, nesse caso, não depende de fatores sanguíneos.

Algumas questões demandam respostas nesta pesquisa: como se dá o processo de escolha de nomes designativos e autodesignativos dentro das redes de parentalidade entre os Wapichana? As redes de parentalidade entre os Wapichana são apenas duas: ou se é parente por afinidade, chamado de "paunary", ou se é parente consanguíneo, nominado de "iriben”. Quais sentidos culturais os nomes designativos trazem em si? Quais implicações sociais recaem sobre o possuidor de um nome pessoal indígena? Logo, o objeto de estudo deste artigo é a construção da noção social de pessoa através das formas antroponímicas de nominação wapichana utilizadas na aldeia Malacacheta, pois, quando se fala em nominação há de se lembrar que

os nomes não designam unidades pré-existentes, reificadas como "sociedades", mas apontam para processos de diferenciação em uma rede. Eles não descrevem uma

${ }^{6}$ A onomástica divide-se em antroponímia (estudos de nomes pessoais) e toponímia (estudos de nomes de lugares).

7 Bebida feita com pasta de beiju.

${ }^{8}$ Espingarda.

9 Chumbo. 
morfologia (um estado), mas indicam pontos de parada, congelamentos passageiros, dos movimentos pelos quais formas sociais são geradas (apontando, portanto, para fluxos). (GUERREIRO, 2016, p. 29)

Presumimos que não é possível entender os sentidos que acompanham os nomes designativos e de autodesignação sem compreender o modo de vida e, sobretudo, a lógica das pessoas no que diz respeito às formas específicas como elas encaram o espaço em que vivem, sem perder de vista, nesse caso, a proximidade da aldeia Malacacheta com a capital Boa Vista (cerca de $36 \mathrm{~km}$ ), o que a torna singular, no que tange ao acesso a bens de consumo e novas tecnologias, como a internet e celulares. Adotamos tal cautela em virtude da advertência feita por Gallois (2005), segundo a qual as comunidades indígenas das terras baixas inserem-se em redes de relação mais amplas, cujas conexões variáveis, a propósito, conectam diferentes grupos em espaços de mediação e processos de comunicação, os quais situam-se entre esferas comumente tidas como separadas.

Para Gallois (2005), importa que se promova o intercâmbio entre as visões sobre os povos indígenas e as visões ou autodesignações dessas sociedades sobre si mesmas. Outra questão a ser observada advém do fato de que, entre os Wapichana, quando se atribui um nome designativo pessoal a um nativo, aciona-se aquilo que Marcel Mauss (2003 [1938]) chama de dádiva. O dom presume uma tríade de obrigações, ou seja, dar, receber e retribuir. Dentre as implicações, que incidem sobre o modo de vida do possuidor de nome designativo wapichana, há, por exemplo, a obrigação moral de participar de ajuris ${ }^{10}$, festas de colheitas e festivais de comidas típicas, como a damorida ${ }^{11}$.

A percepção dos nomes pessoais deixa vazar a polifonia da onomástica wapichana. Desse modo, esta pesquisa etnográfica renuncia qualquer presunção autoral cuja tendência seja a de silenciar ou falar pelo interlocutor autorizado. Os escritos etnográficos aqui arrolados supõem aquilo que Wagner (2010) chama de ficção ou, em outras palavras, algo feito ou modelado. A escrita deste artigo subsome-se naquilo que Strathern (2013) chama de segundo campo, cujo desafio supõe a recriação, reflexiva ou imaginativa, do próprio trabalho de campo.

No primeiro momento, apresentamos um breve relato sobre o povo Wapichana, quanto a língua e a disposição geográfica no cenário etnográfico brasileiro; em seguida, identificamos como os Wapichana da aldeia Malacacheta definem a si a partir dos nomes designativos e autodesignativos; no terceiro momento, descrevemos como os processos de comunicação do corpo com o mundo moldam a noção de pessoa. A reflexão que desenvolvemos nas páginas seguintes fundamenta-se em dados etnográficos reunidos durante pesquisas de campo realizadas durante o ano de 2016, na aldeia Malacacheta e na cidade de Boa Vista, entre os meses de outubro e dezembro, e complementadas entre março e dezembro de 2017.

\footnotetext{
${ }^{10}$ Trabalhos coletivos como limpeza de roças, campina do entorno de escolas e igrejas ou vacinação de animais.

${ }^{11}$ Comida preparada com peixe ou carne assada na brasa, com folha de pimenta malagueta, pimenta jiquitaia (famosa pelo ardor), goma de tapioca e sal a gosto.
} 


\section{O povo Wapichana}

Os Wapichana são um povo indígena que, em território brasileiro, estão dispostos entre os rios Uraricoera e Tacutu e, na Guiana inglesa, habitam entre os rios Tacutu, Rupununi e Kwitaro. Em termos linguísticos, pertencem à família Arawak. A literatura antropológica registra diversas formas de grafia para o termo, com variantes que vão do Aruak, Maipure, Maipuran, Aruaque até Maipuran. Adotamos a nomenclatura Arawak por ser aquela que tem prevalecido tanto nas recentes classificações linguísticas quanto em teses e dissertações antropológicas, vide Urban (1992), Ramirez (2001), Florido (2008) entre outros.

Conforme Loukotka (1968), no momento de contato com os europeus, ou seja, no ano de $1639^{12}$, o tronco linguístico Arawak possuía aproximadamente 83 grupos, compondo uma das 718 línguas faladas na Amazônia brasileira. Apesar de tal afirmação, as fontes históricas da época são precárias e escassas o que torna o componente estatístico informado impreciso. Rodrigues (2001) abre divergência e, fundamentado em documentação mais robusta, estabelece para a Amazônia uma densidade linguística estimada em torno de 1273 línguas indígenas faladas na América do Sul quando da chegada dos colonizadores, sendo que desse total 495 línguas compõem o universo linguístico da Amazônia brasileira.

Os Wapichana que vivem no lado brasileiro apresentam um traço peculiar constatado por Franchetto (1988), isto é, os nativos que habitam próximo aos centros urbanos, como Boa Vista, Cantá e Bonfim em geral vivenciam uma situação de bilinguismo ou multilinguismo, ora falam Wapichana ora, português, ora inglês. Como se trata de um caminho linguisticamente espinhoso porque envolve a noção de línguas em contato, o que implica discutir natureza, grau e escala do contato, situamos os leitores quanto a que tipo de bilinguismo fazemos menção: trata-se daquilo que Freire (2011) chama de bilinguismo social ou bilinguidade, haja vista que na aldeia Malacacheta a comunidade funciona com mais de uma língua, embora nem todos os indivíduos Wapichana que compõem a aldeia sejam necessariamente bilíngues. Entre as gerações mais jovens têm prevalecido a língua da sociedade envolvente. Estes últimos materializam de modo consistente aquilo que Condreau (1877, p. 265 apud FARAGE, 1997, p. 33) chama de "índios vestidos", os quais, no decorrer dos anos, subsomem na categoria de "trabalhadores" (FARAGE, 1997, p. 41). Em sentido oposto, a geração mais velha que vive em aldeias mais distantes dos perímetros urbanos tende a cultivar o monolinguismo, com ênfase exclusiva na Língua Wapichana.

Se a família linguística Arawak possui formas distintas de grafia, o próprio termo Wapichana difere em sentido gráfico: segundo Migliazza (1985, p. 60), Wapixana com " $x$ " designa os falantes de duas línguas mutuamente inteligíveis: Wapixana, no Brasil, e Atoraí, na Guiana inglesa, assim o termo grafado com " $x$ " representa a forma aportuguesada (ou traduzida) da referida palavra. Wapichan escrita com "ch" e sem a vogal "a" é a forma como os índios escrevem a palavra na língua nativa, como está registrado na gramática Wapichan paradan idia'na aichapkary pabinak na'ik kadyzyi kid (CAMILO; OLIVEIRA; SILVA, 2015). Wapichana com "ch" é a maneira como os indígenas grafam em português a palavra na aldeia Malacacheta, inclusive com registro gráfico no Paradakary Urudnaa, o dicionário de Wapichana para português e vice-versa (OLIVEIRA; SILVA; SILVA, 2013); Wapishana com sh constitui a forma usual adotada no inglês (FARAGE, 1997). Há também o registro do termo com "sch", ou seja,

${ }^{12}$ A data exposta deve ser relativizada. Segundo Cruz \& Hulsman (2014), a história de contato remonta a momento anterior, algo por volta de 1612 . 
Wapischana utilizado na tese de Cirino (2000). Reiteramos que a convenção aqui adotada grafa a palavra Wapichana com inicial maiúscula e ch ao se referir a este povo como coletividade - os Wapichana. Nos demais casos, grafa-se a palavra com inicial minúscula: os nomes wapichana, as crenças wapichana.

$\mathrm{Na}$ literatura há outras tantas formas de escrita que fazem referência aos Wapichana, de modo que tomamos de empréstimo algumas registradas por Santos (2006) apenas a título informativo: Vapidiana Verdadeiro, Matisana, Wapityan, Wapitschana, Uapixana, Dauri, Attaraye, Atorayu, Aturaiu, Maopitian, Amaripás e Wapichiyana. Tais escritas derivam de duas possibilidades - de um lado, são meras variações gráficas, de outro, atendem a subdivisões dialetais.

A Malacacheta ou Maracachite ${ }^{13}$ aparece em registros escritos dos anos 80 do século XIX, quando o geógrafo francês Henri Condreau fica por 10 meses entre os Wapichana em razão de um alongado período de convalescência, publicando, em seguida, uma conferência chamada de Le contesté francobrésiliene $^{14}$; já a aldeia Malacacheta cruza os olhares dos órgãos oficiais como a Fundação Nacional do Índio (FUNAI) apenas em 1977, sendo que a sua homologação, conforme Cavalcante, Cirino e Erwin (2008), ocorre somente em 1996.

\section{A parentalidade e os atos de nominação pessoal wapichana}

Entre os Wapichana, quando se fala em parentalidade, há dois aspectos a serem observados: primeiro, o processo relacional inaugurado com o casal de enamorados "minxy'y" (namorado) e "minxy'yaba" (namorada) emerge de uma nova unidade familiar chamada de "iribene"; segundo, uma "iribene" supõe um sistema familiar com autonomia e identidade próprias.

Presume-se que uma "iribene" é sucedida (para não dizer substituída) por um "mazidia'u”, que significa um casal em formação. Um "mazidia'u” wapichana supõe um período de criação de uma nova família nuclear, primeiro porque o casal passa a exercer perante a aldeia identidade e autonomia próprias sem desvencilhar-se dos costumes avitos ${ }^{15}$; segundo, porque o novo casal é responsável por dá seguimento às regras, aos costumes e valores nutridos pela coletividade, o que torna o compromisso dos cônjuges com a aldeia algo do campo moral.

No "mazida'u" surge a figura do pai conselheiro chamado na língua nativa de "dary kakinhaupayzu”, cuja função é orientar os mais jovens e instruir os filhos nas tradições da aldeia, como a caça, a pesca e saber portar-se nas reuniões comunitárias e festas de colheita. O "dary" é a primeira referência de liderança que a criança wapichana ("wapichan kuraidiaunaa”) costuma ter.

O namoro wapichana presume um comportamento expressivo que se insere dentro de um sistema complexo de relações afetivas e familiares e exije dos enamorados o compromisso mútuo. Entre os Wapichana a interação afetiva segue algumas etiquetas nativas: na aldeia Malacacheta, tomamos como exemplo o caso de Pimidy (beija-flor) - quando jovem, o moço wapichana enamora-se por uma "kadyny" (menina moça), com a qual se casa em 2003. Seguindo a tradição matrilocal, assenta moradia na casa do pai da noiva. Da união matrimonial nativa, nascem três filhos: Roberto ${ }^{16}$, o primogênito, atualmente com 13 anos; Aristóteles, 6 anos; e João, o caçula, 1 ano. Sobre o casamento, Pimidy diz:

\footnotetext{
${ }^{13}$ Grafia utilizada por Henry Coudreau em 1887. Cf. Farage (1997) e Carneiro (2008).

${ }_{14} \mathrm{O}$ polêmico franco-brasileiro (tradução livre).

15 Que provêm dos avós, ancestrais ou genearcas.

${ }^{16}$ Adoto nomes fictícios para resguardar a identidade dos entrevistados.
} 
O meu casamento teve uma coisa curiosa: eu pedi do pai da minha noiva a filha dele em casamento, ele aceitou, mas em uma reunião comunitária ele nos pegou de surpresa e disse que queria apresentar um casal novo pra comunidade, aí me chamou e chamou a filha dele pra nós se apresentar pra comunidade e convidou a comunidade pra ir pra casa dele que eu ia oferecer uma damorida. Só que nesse dia estávamos sem nada em casa. Mas sei que depois que saímos da frente da comunidade corremos pra casa, pois sabíamos que o povo ia para nossa casa comer damorida, já que meu sogro tinha convidado todos. Sei que matamos uns frangos, sei que fizemos uma damorida simples, mas que todos provaram e ainda conseguimos um caxiri (PIMIDY, 30/10/2017).

O pai da noiva, "dary minxy'yaba”, aceita o pedido de Pimidy e lhe concede o direito de contrair laços matrimoniais com aquela que o beija-flor wapichana se enamora. Todavia, surpreende o jovem casal com um desafio para o noivo ("minxy'y"): ele tem que provar à aldeia que é capaz de prover alimentos, em alusão ao costume wapichana vindo dos tempos dos avós em que o jovem era desafiado a demonstrar habilidades na caça e na pesca em prol do coletivo e, mais do que isso, é necessário honrar a palavra do sogro que havia prometido perante a comunidade que a festa estava garantida, pois o noivo haveria de oferecer damorida aos convidados. Não há outro termo senão desonra imperdoável o descumprimento da palavra do sogro, o casamento está em risco e Pimidy precisa agir.

Em certos casos, a nominação designativa sinaliza traços morais do nominado, como a disposição para o trabalho ("kaydinhaa'u") e a coragem ("ka'itian”) para enfrentar os inúmeros percalços que a vida impõe. O inverso também é verdadeiro, uma pessoa que demonstra preguiça ou má vontade de participar de trabalhos coletivos (os ajuris), assume perante a comunidade uma reputação oposta àquela propiciada por "pidian ma'uzkan” (pessoa forte), que é a de preguiçoso ("zunziu”). Descola (1998) mostra que, na maioria dos povos indígenas amazônicos, a condenação à avareza constitui um princípio moral, desse modo, a preguiça supõe uma forma de desvirtuar a pessoa à medida que a indolência pode ser interpretada como um ato mesquinho com o próprio corpo, tendo em vista que priva a pessoa da capacidade produtiva em favor do coletivo. Entre os Wapichana, um "zunziu” também pode ser aquela pessoa que não vai à caça, logo não tem carne para repartir com os demais, e ainda assim não se furta a receber a carne obtida pela caça de outras pessoas sem que se comprometa com qualquer contrapartida. Em ambos os casos, o que está em jogo são as relações interpessoais.

Segundo Xaburu (27/10/2017), 60 anos, antigo morador da aldeia Malacacheta, uma forma de uma pessoa alcançar a aprovação de um futuro sogro, "imedukuz", é demonstrando capacidade e coragem para trabalhar, provendo peixe ("kupay"), lenha ("zuaakari") e carne ("dynai"). Para os Wapichana, ajudar ("kaminkia'ytan") é um signo de respeito que traz sobre o praticante a boa reputação de nomes designativos de honra. Xaburu cita como exemplo expressões designativas que enchem de orgulho o nominado: ungary iriben kaimenau'u kamin kiaytpan kaydinkizei da'y, "o meu parente é bom e ajuda no trabalho" ou ungary minhayda'y kaimenaibe manawyn, "meu amigo é generoso demais".

Pimidy, embora saiba que não dispõe de muita coisa a oferecer, articula uma solução rápida e eficaz: sabedor que a damorida é uma comida preparada com peixe ou carne assada na brasa, com folha de pimenta malagueta, pimenta jiquitaia, goma de tapioca e sal a gosto, o beija-flor wapichana recorre à criação avícola que dispõe e, juntamente com a noiva e outros parentes, prepara uma damorida com carne de frango, fechando o cardápio com um caxiri, bebida feita 
a partir da fermentação da puba da mandioca. Aos olhos do sogro, Pimidy alcança a imagem de guerreiro ("ba'iakary") e, por honrar a palavra do pai da noiva, ganha prestígio perante a aldeia. Pimidy encara o desafio do sogro e age para tornar-se um par parental aceitável diante da aldeia.

Para os Wapichana, a tríade parental é formada por "pygary" (você), "ungary" (eu) e "waynau" (nós). A relação de cada uma das partes é o que engendra o sentimento de pertença em relação ao coletivo, de modo que quando se fala em casal entre os Wapichana parte-se do pressuposto de que as decisões tomadas na esfera social emanam do casal e não do indivíduo.

O ciclo vital do casal wapichana superpõe três fases sucedâneas: a primeira é designada "baukupa'u" (união) e resulta da fusão afetiva entre, pelo menos, duas pessoas, de modo que, com a fusão de indivíduos distintos, é estabelecido o "waynau" (nós), cujo lastro é erigido em razão das necessidades mútuas e da intimidade em relação ao parceiro; a segunda fase é chamada de "da'atan" (descoberta), momento em que a rotina da convivência dá vazão a aborrecimentos, com efeito as divergências reposicionam na relação a percepção de "pygary" (você) e "ungary" (eu). A terceira fase é denominada de "mazidian", que é o equivalente nativo para casamento consumado, haja vista que a união afetiva já enfrentou os percalços dos primeiros anos de relação e persistiu.

Xaburu explica que, mesmo com o desaparecimento de Tuminkaru ${ }^{17}$, os Wapichana prosseguem com a dádiva da nominação: os ancestrais receberam seus nomes do demiurgo criador e retribuíram nominando a geração seguinte. O ciclo de nominação segue uma rota sucessiva de dar, receber e retribuir e cada ciclo se completa quando se atinge a condição de adulto pleno e a pessoa tornase avô.

\section{Nominação designativa e autodesignativa wapichana}

Para que um nome pessoal indígena exerça agência é preciso que na aldeia haja outras pessoas possuidoras de nomes designativos e autodesignativos e que, de algum modo, interajam em redes de relação social pela via do reconhecimento. Assim um nome pessoal wapichana presume uma espécie de agente secundário, tendo em vista que por meio dele as pessoas fazem circular sua própria agência. Mas, na prática, como isso é possível?

Na concepção nativa, um nome designativo trata-se de uma forma simbólica de se socializar o corpo, transformando-o em atitude, sentimento e modos de ser. A designação é uma forma de nominação atribuída por terceiros mediante a observação dos possíveis trejeitos que a pessoa a ser nominada possui. Pode ocorrer, também, em virtude de eventos ocorridos no decorrer da vida das pessoas, como nascimento, casamento ou circunstâncias significativas na vida pessoal, como momentos festivos e outras situações que possam afetar individualmente alguém.

$\mathrm{Na}$ aldeia Malacacheta, a atribuição de nomes designativos ocorre de três modos: um nome de batismo cristão, um nome pessoal indígena e nomes jocosos. Ambos podem coexistir por tempo indeterminado e o segundo é dotado de uma plasticidade ou uma mutabilidade possível, pelo menos em escala maior que o primeiro, uma vez que não requer trâmites legais e alongadas burocracias para a mudança, sendo o reconhecimento a força motriz que dá permanência a

${ }_{17}$ Demiurgo criador dos Wapichana. 
um nome pessoal wapichana. Do ponto de vista da antroponímia ${ }^{18}$, são essas as três formas de nominação que se manifestam na aldeia. Perguntado sobre nominações designativas, Xaburu assim relata:

\begin{abstract}
Quando eu era criança lembro que todo mundo só chamava meu pai pelo nome wapichana dele, Mukau, que é a arma do branco, a espingarda. Os mais velhos só chamavam ele assim. Pra falar a verdade, eu só vim saber o nome dele de branco depois de grande. Já minha mãe eu num lembro se ela tinha nome wapichana, aliás, ter ela tinha, mas eu num lembro. Meu irmão até hoje a gente chama ele de Wizchip, que é mucuim (04/12/2017).
\end{abstract}

Ao rememorar as formas de nominação designativa, Xaburu mostra como na família dele a tradição de nominação pessoal nativa é uma realidade nutrida com respeito e levada avante. O pai havia recebido a nominação dada pelos próprios pais e retribui nominando um dos filhos de mucuim em Língua Wapichana. Como o mucuim é um ácaro cuja mordida provoca coceiras intensas, a nominação sugere na ótica nativa um menino peralta, que traz perturbações ao sossego alheio.

Os atos designativos de nominação são fabricados por normas coletivas ou por convenções culturais. Nominar implica agir sobre a pessoa, produzindo nela formas de percepção sobre si. DaMatta, Seeger e Viveiros de Castro (1987) defendem que no pensamento indígena sul-americano o que se persegue é a produção social da pessoa. Na aldeia Malacacheta, os nomes designativos sinalizam atos de diferenciação consciente que se sobrepõem a um fundo de similaridade comum, que é a alma - um elemento que singulariza uma pessoa frente às demais.

Conforme Xaburu, a nominação designativa é precedida de observações por parte do nominador. Este endereça olhares furtivos para quem receberá a nominação: o menor trejeito não pode ser desconsiderado. Mas o que se observa? A condição de possibilidade para uma nominação designativa depende do trejeito de quem será nominado: se a fala é estridente, suave ou faz lembrar a vocalização dos pássaros; se o andar imita o jeito esguio e faceiro de seres da floresta; se o olhar é dissimulado como o da raposa ("Waryzu"). A nominação designativa depende de como o nominador percebe o trejeito daquele que será nominado, o que tende a gerar tensões familiares nos processos de atribuição de nomes pessoais. A tensão se dá quando a pessoa nominada não se sente representada pelo nominativo pelo qual foi designada, o que geralmente desencadeia um processo de autodesignação, ou seja, a pessoa escolhe um nome pessoal para si conforme a percepção que ela tem de si.

A condição física e o estado emocional da pessoa também suplementam a nominação designativa, seja pela permanência ou pela transitoriedade do fato que enseja o ato de nominar: uma pessoa de estatura pequena é chamada de "pidian kaikesudi'u"; uma pessoa de olhos castanho escuro, "pidian awyn pudidi'u"; um homem fraco, "daunaiura kapatin"; uma pessoa triste, "pidian xanuka'u”; e uma pessoa gorda, "pidian kakiwini'u”.

Um nome autodesignativo, por seu turno, presume uma autoimagem que o portador do nome tem de si e deseja partilhar com o coletivo. A autodesignação pessoal é uma das modalidades que os Wapichana chamam de ungary yy mixiu - "meu nome verdadeiro". A ideia é a de que há um outro nome postiço, falso, que serve de máscara social, que é o nome de branco. Um dos maiores apologis-

${ }^{18}$ A expressão Antroponímia foi utilizada pela primeira vez em língua portuguesa, em 1887, pelo filólogo português Leite de Vasconcelos, sendo definida como um estudo dos nomes individuais, incluindo sobrenomes e apelidos (CARVALHINHOS, 2007). 
tas e incentivadores do processo de autodesignação wapichana, o professor e "kwad pazo ${ }^{19 "}$ Xaburu relata como ocorreu com ele a autodesignação nativa:

\begin{abstract}
Xaburu: - Eu estava em uma reunião no Moskow, em 1992, e disse aos parente, a gente precisa escolher um nome pra ser chamado em Wapichana, um nome que a gente se identifique. Eles falaram assim: "mas você está falando em português". Eu comecei a falar em wapichana e eles começaram a entender a proposta. Todo mundo parou e ficou em silêncio para escolher um nome wapichana. Claro! Só aqueles que não tinham. Depois de um tempo, eu disse eu quero ser chamado de Xaburu. Xaburu é uma bebida feita com pasta de beiju, que só presta pra ser tomada até dois dias, depois não presta. Todo mundo pode tomar, não é como caxiri, paracari, até criança bebe. Depois daquele dia, todo mundo começou a me chamar de Xaburu. Tem gente que nem sabe meu nome de branco, só me chama de Xaburu e quando sabe meu outro nome diz: "pois eu só conhecia ele como Xaburu". (04/12/2017)
\end{abstract}

A autodesignação é mutável, permanece enquanto faz sentido para a comunidade, pois de nada adianta alguém usar um nome autodesignativo que não é reconhecido na aldeia. Se os nomes designativos wapichana são passíveis de mudança, não é diferente com as nominações de autodesignação. Desde os antigos Tupi, a mudança de nome sinaliza uma troca de perspectiva, como mostra Viveiros de Castro (1986; 2002), ou seja, os nomes pessoais são pontos de vista que não se desvencilham dos significados presentes na visão coletiva dos nativos. Na aldeia Malacacheta, a partir do momento que uma pessoa não se reconhece mais com o nome designativo, que lhe é atribuído, pode escolher um nome de autodesignação que atenda seus anseios de reconhecimento.

Entre os Wapichana, os nomes jocosos (terceiro tipo de nominação pessoal) são aqueles que são atribuídos em conformidade com atributos físicos e morais de uma pessoa a fim de provocar a zombaria e que, por serem formas circunstanciais e temporárias de nominação, não serão destrinchados no presente artigo.

\title{
A noção de pessoa para os Wapichana
}

A criança wapichana ao nascer geralmente não recebe nenhum nome indígena ou de branco, pois os pais, "darynau”, entendem que a pouca idade é justificativa suficiente para não se atribuir à criança algo com um peso ontológico demasiado, ou seja, um nome pessoal - "pidian yy". Por um ano, o designativo familiar a ela endereçado é "ximensud” (termo nativo genérico para criança).

Quando uma criança wapichana nasce ainda não está apta para receber um nome designativo, o ato demanda certo tempo, que pode variar de cada família para outra. A criança recém-nascida ainda não possui status de pessoa. A ideia é que os ossos pueris são fracos e falta à criança o ânimo mais vigoroso do espírito: a fala polida. Lopes da Silva (1986) indica fato análogo entre os Xavante. A autora afirma que a não nominação das crianças não presume insignificância dos nomes pessoais, mas ocorre devido a carga ontológica ser demasiadamente pesada para o corpo frágil da criança.

Uma vez nascida a criança, os "darynau" procuram observar os ritos de pós-nascimento como, por exemplo: o pai, "dary", resguarda-se de atividades que exigem esforço maior em prol da saúde do filho, as caçadas ficam de lado; a mãe, "daru", do recém-nascido cumpre os dias de repouso; familiares e amigos revezam-se na ajuda ao casal. $O$ "ximensud" (bebê que ainda não possui nome), alheio a tudo, apenas se preocupa em saciar a fome. Os nativos creem que a não 
observância dos referidos ritos pode atrair contra a criança as forças contrárias de espíritos. Nesse caso, costuma-se dizer que "Daudawyz ${ }^{20}$ zamtan kuraidiaunaa durunaa", ou seja, "Daudawyz pegou o espírito da criança" (XABURU, 05/09/2017).

Nas terras baixas, uma ideia nativa recorrente é a de que o nome, mística ou simbolicamente, é acrescentado e até mesmo acoplado ao corpo: Os Desana o chamam de segundo corpo, ainda que seja alma (ANDRELLO, 2006; 2010); os Kaxinawá presumem que o nome é algo simbólico que se estende sobre a pele (McCallum, 1999); os Wapichana, por seu turno, creem que a nominação pessoal é uma alma-nome ("durunaa yy") que torna o indivíduo uma pessoa (LIMA, 2018), assim os aspectos espirituais que o nome porta são considerados de ordem social.

Conforme as palavras de Pimidy (04/12/2017), a aquisição de nomes pessoais "não é de qualquer jeito". Há nomes que podem designar características físicas de um indivíduo: "Kawaru midiay’yziu” (cavalo magro), "Mis'u kakiwini'u” (carapanã gordo); e há, também, designações que não apenas derivam de comportamentos, trejeitos do nominado, mas do estado de espírito que ele exibe diante da comunidade: "Sukuku kunaikii" (sabiá alegre), "Tubuchi kibia'u” (caju amargo), "Kapaxi tu'uruba'u” (tatu valente).

Os nomes pessoais wapichana podem ser dados, recebidos e retribuídos em qualquer idade. A ressalva que se faz é a seguinte: quem porta a nominação deve, de fato, corresponder à simbologia que o nome sugere. Se uma pessoa é designada de "Wamu" (cigarra) supõe-se que possui uma voz estridente ou costuma cantarolar. Como os trejeitos de uma pessoa geralmente são mutáveis ao longo da vida, existe a possibilidade de alguém comportar nomes designativos e jocosos ao mesmo tempo e, em dadas situações, ser referido por meio de um tecnônimo, como "inhawyz ungary dary" - o irmão do meu pai. 


\section{Considerações finais}

Para os Wapichana, portar um nome designativo ou de autodesignação configura um atributo de pessoalização do sujeito. Pais, mães, avôs e avós wapichana são na aldeia mais do que agentes de mobilização da noção de paternidade e maternidade: ao nominarem os filhos com nomes pessoais nativos, eles acionam assimetrias persistentes no campo da parentalidade, pois, de um lado, pelo nome atribuído, a criança adquire projeção social como ser nominado; de outro, pela via da nominação pessoal se imprime na criança a marca social do reconhecimento entre os parentes. Com isso, a nominação pessoal reforça o vínculo familiar e acompanha a pessoa no decorrer da vida, seja em eventos matrimoniais, acontecimentos filiativos, celebrações, festas e reuniões comunitárias.

$\mathrm{O}$ ato de nomear procede de um esforço cultural que demanda convenções sociais e critérios sancionados pelo coletivo, desse modo, para se compreender o processo de construção da pessoa entre os Wapichana, não se pode perder de vista como cada Wapichana se apropria da ideia de parentalidade, no sentido de conceber e colocar-se no mundo. Em outras palavras, os nativos tecem imagens sobre si a partir de designações e autodesignações e isso engloba desde razões morais na escolha de um nome quanto apelos à cosmologia nativa.

Nomeia-se para trazer à existência a alma das coisas, evoca-se um nome para dar vitalidade à cultura, pronunciam-se nomes próprios para se reafirmar as percepções designativas e as formas polifônicas de autodesignação entre os Wapichana. Um nome pessoal nativo é um modo de reconhecer iguais e fazer-se reconhecido entre eles, é afirmar-se enquanto sujeito autônomo, de modo que nominar implica autodeterminar-se como povo, como grupo social, como nativo, como parente ("paunary" ou "iriben") e como pessoa. 


\section{Referências}

ANDRELLO, Geraldo. Cidade do índio: transformações e cotidiano em Iauaretê. São Paulo: editora UNESP, 2006.

. Falas, objetos e corpos Autores indígenas no alto rio Negro. RBCS, São Paulo, n. 73, 2010, p. 5-26.

CALAVIA SÁEZ, Oscar. Nada menos que penas nomes: os etnônimos seriais no sudoeste amazônico. Ilha, Florianópolis, UFSC/ PPGAS, n. 2, 2016, p. 149-176.

CAMILO, Maurício; OLIVEIRA, Kimi da Silva; SILVA, Maria Shirlene de Sousa. Wapichan paradan idia'na aichapkary pabinak na'ik kadyzyi kid. Rio de Janeiro: Museu do İndio, 2015.

CARNEIRO, João Paulo Jeannine Andrade. A morada dos Wapixana: atlas toponímico da região da Serra da Lua-RR. Dissertação de Mestrado, Linguística, USP, 2008.

CARVALHINHOS, Patricia de Jesus. As origens dos nomes de pessoas. Revista Eletrônica de Linguística, São Paulo, a. 1, n. 1, 2007, p. 1-18.

CAVALCANTI-SCHIEL, Ricardo. Para além de terras altas e terras baixas: modelos e tipologias na etnologia sul-americana. Revista de Antropologia, São Paulo, USP, n. 2, 2014, p. 251-290.

CAVALCANTE, Olendina de Carvalho, CIRINO, Carlos Alberto Marinho, FRANK, Erwin Heinrich. Nossa terra: as relações etnoambientais dos Wapishana da terra indígena da Malacacheta/Roraima. Revista do Núcleo Histórico Socioambiental - NUHSA, n. 2, 2008, p. 37-46.

CIRINO, Carlos Alberto Marinho. A "Boa Nova” na Língua Indígena: contornos da Evangelização dos Wapischana no século XX. Tese de Doutorado, Antropologia Social, PUC, 2000.

CRUZ, O. S., \& HULSMAN, L. A Brief History of the Guianas: From Tordesillas to Vienna. Boa Vista: Editora da Universidade Federal de Roraima, 2014.

DAMATTA, Roberto; SEEGER, Anthony; VIVEIROS DE CASTRO, Eduardo Batalha. A construção da pessoa nas sociedades indígenas brasileiras. In: OLIVEIRA, João Pacheco de. Sociedades indígenas e indigenismo no Brasil. Rio de Janeiro: Marco Zero, 1987, p. 11-30.

DESCOLA, Philippe. Les affinités sélectives: alliance, guerre et prédation dans l'ensemble jivaro. L'Homme, Paris, n. 33, 1993, p. 171-190.

. Estrutura ou sentimento: a relação com o animal na Amazônia. Mana, Rio de janeiro, v. 4, n. 1, 1998, p. 23-45,

FARAGE, Nádia. As flores da fala: práticas retóricas entre os Wapishana. Tese de Doutorado, Literaturas de Língua Portuguesa, USP, 1997.

FLORIDO, Marcelo Pedro. As parentológicas Arawá e Arawak: um estudo sobre parentesco e aliança. Tese de Doutorado, Antropologia Social, USP, 2008.

FRANCHETTO, Bruna. Levantamento sócio-linguístico nas malocas Napoleão (Makuxi) e Taba Lascada (Wapichana). Boa Vista: [S.ed.], 1988.

FREIRE, José Ribamar Bessa. Rio Babel: a história das línguas amazônicas. Rio de janeiro: EdUERJ, 2011. 
GALLOIS, Doninique Tilkin. Introdução: Percursos de uma pesquisa temática. In: GALLOIS, Doninique Tilkin. (org.). Redes de relações nas Guianas. São Paulo: Associação Editorial Humanitas, 2005, p. 7-22.

GOODY, Esther. Parenthood and social reproduction: fostering and occupational roles in West Africa. London: Cambridge University Press, 1982.

GUERREIRO, Antonio. Do que é Feita uma Sociedade Regional? Lugares, Donos e Nomes no Alto Xingu. Ilha, Florianópolis, UFSC/ PPGAS, n. 2, 2016, p. 23-56.

HUGH-JONES, Stephen. Nomes secretos e riqueza visível: nominação no noroeste amazônico. Mana, Rio de Janeiro, UFRJ, n. 8, 2002, p. 45-68.

LIMA, Fabio de Sousa. Formas de nominação pessoal wapichana na aldeia Malacacheta. Dissertação de Mestrado, Antropologia Social, UFRR, 2018.

LOUKOTKA, Čestmír. Classification of South American Indian Languages. Los Angeles: UCLA Latin American Center, 1968.

MAUSS, Marcel. Sociologia e Antropologia. São Paulo: Cosac Naify, 2003 [1938].

MCCALLUM, Cecilia. Aquisição de gênero e habilidades produtivas: o caso Kaxinawá. Revista Estudos Feministas, Florianópolis, n. 1, 1999, p. 157-175.

MENGET, Patrick. Em Nome dos Outros. Classificação das Relações Sociais entre os Txicáo do Alto Xingu. Lisboa: Museu Nacional de Etnologia, Assírio \& Alvim, 2001.

MIGLIAZZA, Ernesto. Grupos linguísticos do Território Federal de Roraima. Atas do Simpósio sobre a Biota Amazônica. [s.l], n. 2, 1985. p. 82-102.

OLIVEIRA, Odamir; SILVA, Bazilio da; SILVA, Nilzimara de Souza. Paradakary urudnaa: dicionário Wapichana/português, português/Wapichana. Boa Vista: EDUFRR, 2013.

RAMIREZ, Henri. Línguas Arawak da Amazônia Setentrional: comparação e descrição. Manaus: EDUA, 2001.

RODRIGUES, Aryon Dall'Igna. Biodiversidade e diversidade etnolinguística na Amazônia. In: SIMÕES, M.S. (Org.). Cultura e biodiversidade entre o rio e a floresta. Belém: UFPA, 2001, p. 269-278.

SAHLINS, Marshall David. What kinship is... and is not. Chicago: The University of Chicago Press, 2013.

SANTOS, Manoel Gomes dos. Uma gramática do Wapixana (Aruák) - aspectos da fonologia, da morfologia e da sintaxe. Tese de Doutorado, Linguística, UNICAMP, 2006.

SILVA, Araci Lopes da. Nomes e amigos. São Paulo, FFLCH/USP, Coleção Antropologia, 1986.

SILVA, Marcio. O grande jogo do casamento: um desafio antropológico e computacional em área de fronteira. Revista de Antropologia. São Paulo, USP, v. 60, n. 2, 2017, p. 342-355.

STRATHERN, Marilyn. Fora de contexto: as ficções persuasivas da antropologia. São Paulo: Terceiro Nome, 2013. 
URBAN, Greg. A história da cultura brasileira segundo as línguas nativas. In: CARNEIRO DA CUNHA, Manuela (Org.). História dos índios no Brasil. São Paulo: Companhia das Letras, 1992, p. 87-102.

VIVEIROS DE CASTRO, Eduardo. Araweté: os deuses canibais. Rio de Janeiro, Jorge Zahar Editor, 1986.

. Os pronomes cosmológicos e perspectivismo ameríndio. Mana, Rio de Janeiro. v. 2. n. 2, 1996, p. 115-144. \& Naif, 2002.

A inconstância da alma selvagem - e outros ensaios. São Paulo: Cosac

WAGNER, Roy. A invenção da cultura. São Paulo: Cosac Naify, 2010. 